\title{
O SISTEMA DE VIGILÂNCIA EPIDEMIOLÓGICA SOB A CRISE DO SETOR SAÚDE
}

\author{
Beatriz A. Fortes Perrenoud * \\ José Cassio de Moraes**
}

Discute as intervençbes que precederam a atual crise do Sistema de Vigilancia Epidemiologica do Estado de Sáo Paulo e os pressupostos que devem orientar as propostas de soluçio. Considerando as relaçoes com os nfveis Federal e Municipal, buscase adequar o atual Sistema de Vigilancia Epidemiologica ds diretrizes do Sistema Único de Saúde.

\section{INTRODUÇÃO}

Sentiu-se a necessidade de se organizar e publicar o núcleo da idéia que se vem formando no processo de discussóes sob o tema-título. Tais debates estão em curso, desde o segundo semestre de 1991, entre os "profissionais-militantes" desta área da saúde coletiva no Estado de São Paulo: serviços, academia e associações. Embora seja, em parte, conseqüência deste processo (ainda em curso), o conteúdo deste artigo é de responsabilidade dos autores.

Em que pese não ser pertinente, neste artigo, o debate sobre o que seja "vigilancia", "vigilância epidemiológica" e "organizaçăo sistémica", reconhece-se que, sob a denominaçăo de Sistema de Vigilancia Epidemiológica, encontra-se a padronização conceitual e de propostas de controle de alguns agravos à saúde. Para a quase totalidade destes, existe o Sub-sistema de Informações para Doenças de Notificação Compulsória. Atualmente, no Estado de São Paulo, săo de notificaçăo compulsória: acidentes do trabalho, doenças profissionais e do trabalho***, acidente por animal peçonhento, AIDS, cólera, dengue, difteria, doença de Chagas (forma aguda), doença meningocócica e outras meningites, encefalite por arbovírus, esquistossomose,

- Medicasaniariea do Centro de Vipilancia Epidemiologiea da Secrearia de Bando da Saude-SP.

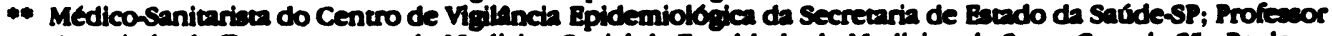
Aseociado do Departamento de Medicina Soctal da Faculdade de Medicina da Santa Casa de Sto Paulo.

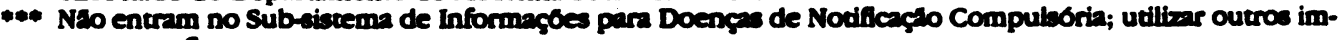
pressos e fluros. 
febre amarela, febre purpúrica do Brasil, febre tifóide, hanseníase, leishmaniose cutâneo-mucosa, leishmaniose visceral, leptospirose, malária, peste, paralisias e paresias agudas e flácidas de qualquer etiologia em menores de 15 anos; poliomielite, raiva humana, sarampo, (ambulatorial e hospitalar), sífilis congênita, tétano, tracoma, tuberculose, varíola, surto de hepatite, surto de conjuntivite, outros surtos e epidemias e agravos inusitados à saúde.

Paralelamente, o nível central do Sistema de Vigilância Epidemiológica-SP (Centro de Vigilancia Epidemiológica), desenvolve outras abordagens epidemiológicas (pesquisa, levantamento de mortalidade e análises comparativas entre dados de diversas morbidades, obtidos de fontes secundárias) para algumas doenças não-infecciosas e outras infecciosas.

Seleciona-se uma entidade nosológica para compor, ou não, o elenco das Doenças de Notificação Compulsória após estudo de sua magnitude, gravidade, vulnerabilidade, e transcedéncia social. Pondera-se também a existência de fatores de risco ou de fatores prognósticos suscetiveis à intervenção, a identificação de subgrupos da população sujeitos a um alto risco de experimentar o dano, a potencialidade do impacto de uma intervenção sobre os fatores de risco (risco atribuível), a correlação entre o risco e a operacionalidade da intervenção com a eficácia a ser obtida e, finalmente, a possibilidade de compatibilização das diversas intervenções, nos programas de controle polivalentes.

Se esta tradicional abordagem a tais agravos não nega a globalizante "vigilancia à saude" a ser desenvolvida nos sistemas locais de saúde, tão pouco desaparece nesta.

É fundamental que se diferencie claramente vigilância epidemiológica de controle sanitário.

O conceito de vigilância epidemiológica que se adota é o de Fossaert et al.(1) modificado, que a caracteriza como: "o conjunto de atividades que permite, a qualquer momento, reunir a informação indispensável ao conhecimento da história natural da doença, detectar ou prever qualquer mudança que possa ocorrer em conseqüência de alteraçōes nos fatores condicionantes, com a finalidade de recomendar, sobre bases firmes, as medidas indicadas, eficientes, que a levem à prevenção e controle da doença. Em si- 
tuações especiais, executar as ações de controle" .

O conceito de controle sanitário, aqui, transcrito, foi retirado da tese de doutorado de Waldman(2).

" O controle sanitário de produtos de consumo humano, de riscos ambientais e do exercício profissional na área biomédica, (....) deve ser entendido como um processo desenvolvido por um conjunto de atividades implementadas de forma coordenada e com um objetivo comum que é poder oferecer uma boa qualidade de vida à população. Neste sentido e amplitude, é regido por legislação específica, cujo cumprimento deve ser garantido pelo poder de polícia do Estado, explicitado pela fiscalização sanitária e, por sua vez, assegurado pelo poder judicíario que deve oferecer à população a garantia do respeito aos direitos de todos os cidadãos" .

Isto feito, observa-se, hoje, na vigilancia epidemiológica de São Paulo, duas lacunas. Trata-se da necessidade de:

- organizar e adequar o Sistema de Vigilancia Epidemiológica, às transformações que estão ocorrendo no setor saúde. Cada micro-regiăo, município, e região do Estado, precisa ter suas atribuições claramente estabelecidas e articuladas sistemicamente.

- estabelecer uma coordenaçăo dos vários níveis e órgãos do Sistema de Vigilancia Epidemiológica, desenvolvendo-os nas suas potencialidades. Deve-se continuar a elaborar e divulgar as bases técnicas dos agravos sob vigilancia epidemiológica, normalizar e coordenar o Sistema de Vigilancia Epidemiológica no ambito estadual. As análises epidemiológicas devem buscar subsidiar o planejamento dos municípios e do Estado.

Neste processo não pode ser postergado o entendimento de fracassos do passado e do presente. Desde a formulaçăo da norma 7 (1974 - listagem de doenças de notificaçăo compulsória pré-Sistema de Vigilancia Epidemiologica)(3), estão previstos os instrumentos e perfil de pessoal para que and́lises sejam realizadas rotineira e sistematicamente, nos diferentes niveis do Sistema de Vigilancia Epidemiológica, atendendo às respectivas necessidades. Isto raramente acontece. Quanto ao controle, há necessidade de abordagens relativamente padronizadas, o que vem funcionando. Adicionalmente necessita-se garantir assessoria necessária aos municípios, regióes e 
alguns órgãos especiais. Isto não ocorre na rotina do Sistema de Vigilancia Epidemiológica-SP e é preciso que tal assessoria seja formalizada dentro da estrutura existente, prevendo os recursos que tal questão compreende.

\section{CONJUNTURA E PROPOSTAS}

Na interrelação da proposta de Sistema Único de Saúde - com descentralização e municipalização da saúde e a administração federal estruturada sobre outras bases - não foram poucos os conflitos existentes na esfera estadual. A experięncia tem mostrado o quanto uma proposta politicamente progressista e tecnicamente correta e pertinente, pode ser distorcida. dos:

Quanto ao Estado de São Paulo, três momentos precisam ser recupera-

- A reestruturação administrativa da Secretaria de Estado da Saúde, ocorrida entre 1985 e 1986, quando, sob a argumentação de que se precisava de estruturas ágeis e leves, foi desfeita a estrutura existente. Na substituição foi esquecida a formulação de políticas que viabilizassem o desenvolvimento das diversas instituições. Restou o fim do preenchimento por concurso público de funçóes de direção nas regionais de saúde.

- A desativação da carreira de médico sanitarista, em 1987, atingiu o Estado inteiro, mas causou situação particularmente difícil na regiāo da Grande São Paulo. Nesta ocasião, as lideranças sindicais médicas, não sanitaristas, compactuaram com o ocorrido. Desde então, também as chefias de nível local da rede própria do Estado (e na maioria dos municipios), vêm sendo preenchidas por indicaçăo e não por concurso público.

- Mais recentemente tem-se enfrentado o descaso para com os quadros técnicos de institutiçỏes importantes. São particularmente caros à vigilância epidemiológica, o laboratório de saúde pública e o sistema de informaçōes em saúde. Não cabe neste artigo detalhar, mas aponte-se que, somente em 1989, houve a junção do Sistema de Vigilancia Epidemiológica com o seu sub-sistema de informaçőes, sob comando único. Isto, porém, só foi garantido a nível central e com defasagem de recursos humanos e materiais. Os computadores foram adquiridos, mas os recursos humanos desta área não vêm resistindo à política salarial do Estado.

Municípios vêm absorvendo as conseqüências do ocorrido com o nível 
local e, em parte, com o nível regional da Secretaria de Estado da Saúde. Isto talvez explique a pequena reação dos setores envolvidos.

No Estado de São Paulo, há muito que as orientações técnicas não passam por influências políticas individuais de qualquer ordem. Isto sem dúvida decorre da respeitabilidade conquistada pelo Centro de Vigilancia Epidemiológica. O mesmo não se pode dizer das limitações econômicas, sejam aquelas necessárias ao desenvolvimento de projetos, seja aquela referente ao salário dos profissionais que aí trabalham. Muitos têm sido cedidos às prefeituras e recentemente têm feito concursos para estas instâncias.

Não se visualiza um bom substituto para o atual nível central do Sistema de Vigilância Epidemiológica-SP. Em que pese as dificuldades e a necessidade de transformações, anos de investimento na formação de recursos humanos não podem ser desprezados.

De um lado, é indiscutível que é no âmbito municipal e em regiōes dos municípios maiores, onde os dados melhor retratam a realidade local. Permitem, assim, a elaboração de estratégias dirigidas para estratos específicos da população, com adequação dos recursos para o controle das doenças de notificação compulsória, bem como a integração com outros programas de saúde. Por outro lado, as doenças transmissíveis e seus determinantes não respeitam os limites administrativos, havendo necessidade de constantes análises em níveis geográficos de maior abrangencia, com a necessidade de detecção de riscos diferenciados, o mesmo ocorrendo no planejamento das açōes de controle e na avaliaçăo desta intervençăo.

A ninguém, seriamente comprometido com as questóes em pauta, interessa a destruiçăo da estrutura estadual e, é preciso estar atento para que o Estado não seja desresponsabilizado de atribuiçóes que são precipuamente suas. Assim, pondere-se que:

1. Trata-se de um específico Sistema de Vigilancia Epidemiológica que existe e está organizado sobre bases teóricas conhecidas, criticáveis e passiveis de revisão; com instrumentos para a coleta homogeneamente distribuídos em todo o Estado e uma análise de dados padronizada em todos os níveis; com uma equipe de nível central, tanto quanto possível, especializada em grupos de doenças. 
2. No Manual de Vigilância Epidemiológica-SP(3), salienta-se a importância de distingüir Vigilância Epidemiológica de Vigilância Sanitária, pois, enquanto a segunda se aplica a indivíduos, no sentido de se detectar o mais precocemente possível os sinais da doença, a primeira se aplica às comunidades no sentido de conhecer a dinâmica das doenças.

Mais recentemente os serviços de controle sanitário agruparam-se sob a denominação de "vigilância sanitária" . Tal fato tem causado confusões, posto que, o serviço estadual de controle sanitário compreende atividades diversas. Estas, não se articulam sistemicamente e, a não ser em algumas atividades específicas, não compõem " sistemas de vigilância".

Tal constatação não diminui a importância social dos serviços de controle sanitário. O que se objetiva é deixar transparente a inexistência de um ramo de conhecimento próprio " das vigilâncias" .

Em algumas intervenções, faz-se necessária a articulação entre o Sistema de Vigilancia Epidemiológica, a clínica médica, o laboratório de saúde pública e os serviços de controle sanitário, dentre outros. Nas Unidades Básicas de Saúde, ambas podem estar sob comando único.

3. O Estado de São Paulo não se limita ao mosaico dos municípios que o compöem. O Sistema de Vigilância Epidemiológica vem sendo adequado para que, ao atender às variadas demandas dos municípios, não perca sua característica sistêmica, o acesso a um banco de dados único, nem a série histórica correspondente às doenças.

4. As normas técnicas são imprescindíveis, dentre muitos outros aspectos, para que os " casos" e os " não casos" sejam padronizados. Só assim poder-se-á continuar a ter dados que permitam comparar um município ou região com outros, e um mesmo local em diferentes momentos.

É uma prática do Centro de Vigilância Epidemiológica sempre elaborar normas com a participação dos vários segmentos da comunidade acadêmica. Este processo, embora moroso, busca garantir a base científica de conceitos e procedimentos, bem como o consenso possível entre 
as várias escolas. Do mesmo modo, existe abertura para que alguns serviços de saúde, de qualidade reconhecida, trabalhem com critérios especiais, retroalimentando o sistema e apontando para a necessidade de revisōes na normalização existente. Da mesma forma, municípios e regiōes do Estado podem e devem avançar para, além de atender à demanda estadual, criar novos cruzamentos de variáveis e/ou incorporar novas variáveis (de estudo), buscando um melhor recorte para a realidade.

5. O domínio da informática garante uma nova agilidade e relacionamento com as diversas instâncias envolvidas no subsistema de informações para Doenças de Notificação Compulsória. Tais informaçōes só serão úteis se os dados estiverem disponíveis ao nível do sistema que os utilizará e no tempo necessário à ação. Certamente as informações necessárias aos diversos níveis do Sistema de Vigilancia Epidemiológica não são as mesmas e algumas adequações se fazem presentes.

6. As pessoas envolvidas com as atividades de normalização e coordenação do Sistema de Vigilância Epidemiológica devem ir se distanciando do perfil polivalente de "vigilantes", rumo ao domínio teórico que permita sejam considerados "epidemiologistas" . Estes, como todos os epidemiologistas, precisam dominar seu objeto de estudo. Daí a proposta de agrupar as doenças por modo de transmissão e especializar as equipes técnicas.

Este percurso fica dificultado quando tais profissionais empregam seu tempo na administraçăo de programas ou, até mesmo, de serviços. Ambas as atividades (administraçăo, planejamento e epidemiologia) são importantes à saúde coletiva, mas năo devem ser confundidas e muito menos exercidas pelos mesmos profissionais.

7. A resoluçăo de duas questőes, ainda está em curso. A primeira diz respeito aos níveis regionais do Sistema de Vigilancia Epidemiológica e considera a necessidade de sua existencia. Na capital, tais regionais devem ser aquelas da Secretaria de Saúde do Município. No restante do Estado, Grande São Paulo inclusive, busca-se formular algo que incorpore a "representaçăo de um conjunto de serviços de vigilancia epidemiológica de vários municípios junto ao nível Central do Sistema de Vi- 
gilância Epidemiológica do Estado", em substituição a uma "representação do Estado, junto aos municípios de uma região" . Tal tarefa não se apresenta fácil. De imediato, deveriam ser estruturados colegiados regionais de vigilância epidemiológica, com a atribuição de elaborar e divulgar análises rotineiras e periódicas sobre a distribuição dos agravos sob vigilancia epidemiológica. Constituir-se-iam em instâncias estritamente técnicas, sem nenhuma atribuição burocrático-administrativa.

A segunda questão diz respeito a um grande número de municípios que não tem condiçōes sequer de execução de ações de vigilância epidemiológica. Tendo como base a idéia de que não se quer um " Estado apenas para municípios pobres" , há que se formular melhor os caminhos que levem ao equacionamento desta questäo, possivelmente através de consórcios de municípios ou equivalente.

8. Preocupaçōes semelhantes têm-se com a esfera federal. Lá, certamente, as soluçōes terão que ser variadas, incorporando a grande diferença existente entre as regiōes (e, aqui, faz-se referencia a grupos de estados vizinhos, com realidades epidemiológicas e estrutura de serviços semelhantes e, não, às regiōes geográficas oficiais). Assim, sempre respeitando a necessidade de que exista compatibilização entre as informaçōes, viabilizando a possibilidade de análise a nível nacional, os estados poderão trabalhar com critérios adequados à sua situaçäo. Cabe ao nível federal garantir que os estados consolidem equipes técnicas de vigilancia epidemiológica e que estas se articulem entre os estados de sua " região" .

Sem dúvida, existe mais de um caminho possível. O que é inaceitável, a nivel municipal, regional, estadual ou federal, é que se faça mais uma aventura administrativa destruindo, ao invés de corrigir, as estruturas existentes. Há que se formular políticas institucionais claras, com as respectivas políticas de recursos humanos, para os órgãos que têm como atribuiçăo específica a esfera estadual, e assim, colocá-los a serviço do Sistema Único de Saúde, com todos os seus pré-requisitos. Aponte-se a importancia de instituiçóes bem estruturadas, que consigam absorver as várias experiencias existentes, dentre as quais destaca-se a proposta de

"vigilancia à saúde", promovendo a revisão da questão da inserçăo do Sub-sistema de Informaçőes para Doenças de Notificação Compulsória. 


\section{BIBLIOGRAFIA}

1. FOSSARRT, P. H.; LLOPIS, A.; TIGRE, C. H. Sistemas de vigilancia epidemiol6gica. Bol. Ofic santt. panamer., 76:512-25, 1974.

2. WALDMAN, E. A. Vigilancia epidemiologica como pratica de saúde pública. Sáo Paulo, 1991. [Tese de Doutorado - Faculdade de Saúde Pública da Universidade de S5o Paulo, 1991].

3. GOVERNO DO BSTADO DE SÃO PAULO/Secretaria de Bstado da Saúde/ Centro de Informaçós de Saúde. Manual de etgillancia epidemiologica: normas e instrugojes. Sto Paulo, 1978. 